\title{
Keep on Going: Apoio à escolha estratégica do estágio curricular
}

\author{
Inês Nascimentol \\ Soraia Ferreira \\ Priscila Rodrigues \\ Faculdade de Psicologia e de Ciências da Educação da Universidade do Porto
}

\section{Resumo}

No presente artigo é apresentado e descrito um projeto de intervenção no domínio da psicologia vocacional designado Keep-on-Going. A intervenção em causa visa apoiar jovens na fase final do processo formativo, na escolha estratégica do contexto de estágio curricular. Tem como base teórica o Modelo de Exploração Reconstrutiva do Investimento Vocacional, e estrutura-se em seis momentos-chave num total de 10 sessões com duas a três horas cada. Participaram na 1. a edição cinco estudantes (do sexo feminino) do 1. ${ }^{\circ}$ ano do Mestrado em Psicologia da Educação. Os resultados da avaliação contínua apontam para valores médios de seis numa escala de $1 \mathrm{a} 7$, em termos da qualidade geral do projeto. Na avaliação de follow-up as dimensões "Evolução na capacidade de escolher" e "Utilidade do projeto", são as mais pontuadas confirmando que a participação no projeto se revelou uma experiência de valor para as estudantes.

Palavras-chave:formação do psicólogo; orientação vocacional; desenvolvimento profissional

\section{Abstract: Keep On Going: Support for the strategic choice of the curriculum internship}

This article presents and describes an intervention project in the field of vocational psychology named Keep-onGoing. This intervention aims to support young people in the final stage of the training process, in the strategic choice of the context of curricular internship. Its theoretical basis is the Reconstructive Exploitation Model of Vocational Investment, and it is structured into six key moments in a total of 10 sessions with two to three hours each. Five female students participated in the first edition of the 1st year of the Master's in Educational Psychology. The results of the continuous evaluation point to average values of six on a scale of 1 to 7 , in terms of the overall quality of the project. In the follow-up assessment, the dimensions "Evolution in the ability to choose" and "Project usefulness" are the highest scores confirming that participation in the project has proved to be a valuable experience for the students.

Keywords: psychologist education; vocational guidance; professional development

\section{Resumen: Keep on Going: Apoyo a la elección estratégica en las prácticas curriculares}

En el presente artículo se presenta y describe un proyecto de intervención en el ámbito de la psicología vocacional designado Keep-on-Going. La intervención en cuestión pretende apoyar a los jóvenes en la fase final del proceso formativo para la elección estratégica del contexto de la práctica curricular. Se tiene como base teórica el Modelo de Exploración Reconstructiva de la Inversión Vocacional, y se estructura en seis momentos clave en un total de 10 sesiones de dos a tres horas cada una. Participaron en la primera edición cinco estudiantes (sexo femenino) del primer año de la Maestría en Psicología de la Educación. Los resultados de la evaluación continua apuntan valores medios de seis en una escala de 1 a 7, en términos de la calidad general del proyecto. En la evaluación de seguimiento, las dimensiones "Evolución en la capacidad de escoger" y "Utilidad del proyecto" son las más puntuadas, confirmando que la participación en el proyecto constituyó una experiencia de valor para las estudiantes. Palabras clave: formación del psicólogo; orientación vocacional; desarrollo profesional

Endereço para correspondência: Faculdade de Psicologia e de Ciências da Educação da Universidade do Porto, Rua Alfredo Allen, 4200-135, Porto, Portugal.

Telefone: (22) 6079-700.E-mail:ines@fpce.up.pt. 
Qualquer que seja a área de formação, o estágio curricular assume-se como um momento crítico de aproximação ao mundo do trabalho e de exploração experiencial das características específicas do exercício profissional que cada estudante escolheu querer para si na vida ativa, e que se reveste ainda de mais importância quando se sabe que os jovens, quando escolhem uma profissão, não avaliam, com frequência, a importância do contexto de trabalho no processo de construção das suas identidades (Brasil, Felipe, Nora, \& Fravetto, 2012). Com efeito, é amplamente reconhecido que esta etapa se destaca pela sua importância e valioso contributo para o enriquecimento pessoal e profissional do estudante, constituindo-se como uma oportunidade para dar continuidade à aprendizagem em local de trabalho, juntando ao conhecimento teórico o conhecimento prático que $\mathrm{o}(\mathrm{s})$ contexto(s) profissional(ais) podem oferecer (Bolhão, 2013). Representa, assim, um período de iniciação à profissão no qual o estudante se confronta, de modo direto, com exigências situacionais e problemas reais da prática na resposta aos quais a sua identidade profissional e estilo de atuação são, processualmente, potenciados (Cardoso, Varanda, Madruga, Escária, \& Ferreira, 2012). Com efeito, espera-se que o estágio curricular constitua uma experiência satisfatória e significativa tanto pelo seu valor como oportunidade privilegiada de formação prática em contexto, como pelo facto de se tratar de um momento facilitador da transição iminente para o mercado de trabalho.

Tendo em vista a otimização desses contributos da experiência de estágio na formação de um profissional de qualidade, é fundamental que o contexto em que o estágio ocorra ofereça ao estudante condições favoráveis à aquisição, ensaio e consolidação de uma gama de competências que, futuramente, lhe permitam sentir-se preparado e seguro para o exercício autónomo da atividade profissional e dispor de um perfil que tenha como atributo a adaptabilidade. O desenvolvimento e aprofundamento desse sentimento de (auto)eficácia certamente se beneficiará da disponibilidade de atitudes e conhecimentos que o/a estudante possa ter vindo previamente a acumular, de um modo mais informal ou formal, durante os anos de frequência da Faculdade, seja na sala de aula e/ou fora dela, nos seus outros espaços de vida. A possibilidade de mobilizar esses recursos face aos desafios do estágio pode, dessa forma, constituir um fator de relevo no sucesso da própria experiência de estágio. A escolha do estágio curricular revela-se, por isso, um momento especialmente sensível na gestão da trajetória formativa pelos estudantes. Contudo, nem todos estarão suficientemente cientes da importância de ponderarem a escolha do local de estágio, contemplando, a montante, análise dos saberes e competências adquiridos e o seu valor instrumental para o desempenho no estágio e, a jusante, os objetivos em termos de aprendizagem e de desenvolvimento profissional, que o estágio lhes poderá permitir alcançar. Esta necessidade foi especificamente observada nos estudantes pré-finalistas da área de Intervenção Psicológica, Educação e Desenvolvimento Humano (IPEDH), do Mestrado Integrado em Psicologia (MIP) da Faculdade de Psicologia e de Ciências da Educação da Universidade do Porto que, na escolha do local de estágio, nem sempre se mostravam capazes de atender a critérios mais complexos do que os que se prendiam com o seu desejo em estagiar em certas organizações, com determinadas populações e/ou em locais mais convenientes, do ponto de vista da sua acessibilidade geográfica. Nas reuniões destinadas à apresentação dos locais de estágio que constituíam a oferta de uma dada área, evidenciava-se a dificuldade dos estudantes em identificarem e argumentarem de modo diferenciado em prol do tipo de estágio que considerariam melhor para si, tendo em conta, por um lado, as suas experiências (formativas e de aprendizagem) prévias e, por outro lado, os objetivos formativos e/ou profissionais em perspetiva.

Acresce que, na maior parte das vezes, esta escolha se realizava sem nenhum contacto anterior, direto ou indireto, dos estudantes com os locais de estágio que, presos nas suas representações, muitas vezes, heteroproduzidas por ex-estagiários nesses locais, não manifestavam especial curiosidade em saber mais sobre tais locais. $\mathrm{Na}$ ausência dessa exploração, os estudantes tendiam a vincular-se dogmaticamente a um local de estágio favorito, o que inviabilizava a sua abertura à identificação de alternativas, e se tornava preocupante face à existência de constrangimentos à obtenção do estágio em causa como o limite do número de vagas e a concorrência de outros interessados, ou a posição do estudante na lista de seriação ordenada em função dos resultados académicos obtidos, até então, e que funciona como critério final relativamente à colocação ou não no local de estágio pretendido. Mostrava-se, assim, indispensável apoiar formalmente os estudantes na escolha crítica da instituição onde pretendiam realizar o seu estágio curricular, razão pela qual foi desenhado e implementado o projeto "Keep-on-going".

Trata-se de um projeto que se assume como uma intervenção psicológica no domínio do desenvolvimento vocacional e cujo principal objetivo foi o de habilitar os estudantes da área de IPEDH do MIP a pensarem e a gerirem estrategicamente as escolhas que pontuam a sua trajetória profissional, a começar pela escolha relativa ao local de realização do seu estágio curricular. Neste âmbito, o projeto procura promover o alinhamento dos critérios de escolha do local de estágio com uma visão estratégica quanto ao tipo de estágio que seria melhor para cada estudante tendo em conta:

a) as suas experiências formativas e não formativas prévias;

b) os objetivos pessoais e profissionais em perspetiva;

c) as condições de mercado e as oportunidades disponíveis. 
O projeto de intervenção foi construído com base nos pressupostos do Modelo da Exploração Reconstrutiva do Investimento Vocacional (Campos \& Coimbra, 1991) que assenta numa visão desenvolvimentista, construtivista e sistémica das escolhas vocacionais. De acordo com esta perspetiva, o desenvolvimento vocacional constitui-se como uma dimensão integradora do funcionamento psicológico global, referindo-se à confrontação da pessoa com tarefas relacionadas com a elaboração, implementação e reformulação de projetos de vida em múltiplas dimensões constituintes do seu percurso. Desta forma, encontram-se em destaque contextos como a educação, a formação e a atividade profissional, em associação com um estilo de vida que abarca o desempenho em diferentes papéis como familiar, social e cultural (Campos, 1991).

Especificamente, o desenvolvimento vocacional realiza-se através da definição de um itinerário pessoal e vocacional entre as diversas alternativas possíveis e implica sucessivas decisões que articulam o que existe no meio, o que é desejado pela pessoa e o que esta é capaz de fazer em termos das suas competências e habilidades (Imaginário, 1990). Coloca-se em evidência a importância da exploração vocacional ao longo do ciclo de vida. Quer isto dizer que cada escolha é significativamente influenciada pelas escolhas que a pessoa foi realizando ao longo da sua vida, por determinação das suas próprias características pessoais e das condições do meio circundante. Assim, a escolha é vista como um processo dinâmico e interativo, resultado de pequenas outras escolhas que vão sendo realizadas e revistas sucessivamente (Coimbra, 1997/1998).

Desta forma, os projetos vocacionais (re)constroem-se ao longo do tempo, tendo em consideração as oportunidades e situações com as quais a pessoa se vai deparando ao longo do seu quotidiano e assimilação do novo com o existente no seu repertório pessoal (Gonçalves, 2000). Campos e Coimbra (1991) afirmam que o desenvolvimento vocacional se processa através das relações que a pessoa estabelece com as diferentes dimensões constituintes da realidade, atendendo às experiências e acontecimentos que vai vivenciando nos múltiplos contextos de vida em que se desenvolve e participa. Estes implicam o questionamento de projetos de vida anteriores e a construção de novos investimentos. Neste seguimento, aspetos como a exploração e o investimento são determinantes, pois é mediante a exploração que a pessoa transforma e reconstrói os seus investimentos vocacionais (a forma como antes se relacionava com a realidade), atribuindo novos significados (Campos \& Coimbra, 1991).

A designação atribuída ao projeto - Keep-on-Going - inspira-se e enquadra-se nesta lógica de otimização da coerência entre o tempo passado, presente e futuro da(s) escolha(as) vocacional(ais) dos estudantes do ensino superior. Pretende acentuar duas ideias principais: (1) a de que, apesar da sensação de descontinuidade trazida pela transição para o estágio, as fases que se seguem na sua trajetória formativa fazem parte de um processo mais longo que se iniciou (muito) antes da escolha do próprio curso de Psicologia e que se prolongará para além do estágio iminente; (2) a de que é fundamental que eles/as próprios/ as chamem a si a responsabilidade de o fazer seguir na direção dos seus objetivos. Será esse projeto de intervenção que o presente artigo se propõe descrever do ponto de vista metodológico sendo que, complementarmente, são apresentados alguns dados da sua avaliação (contínua, final e de follow-up) com base em indicadores subjetivos (perceções dos participantes quanto à importância e utilidade da intervenção).

\section{Metodologia do projeto Keep-On-Going}

Em consonância com a proposta de intervenção do Modelo de Exploração Reconstrutiva do Investimento Vocacional (Coimbra, Campos, \& Imaginário, 1994), do ponto de vista metodológico, o projeto Keep-on-Going privilegiou a identificação, reflexão e discussão dos principais acontecimentos, internos e externos, que foram sendo experienciados pelos/as estudantes ao longo do tempo, uma vez que se considera que aqueles são suscetíveis de produzir implicações importantes nas escolhas subsequentes. De igual modo, procurou fazer-se "acontecer" intencionalmente na intervenção algumas outras vivências que permitissem ativar a exploração (re) construtiva desses referenciais, de forma a desencadear processos de (re)significação que pudessem revelar-se consequentes na definição estratégica do local de estágio potencialmente mais satisfatório em termos pessoais. Indo ao encontro dos principais aspetos que caracterizam o Modelo de Exploração Reconstrutiva (Coimbra et al., 1994), o projeto procurou, por isso, proporcionar aos estudantes: a) a participação e envolvência em experiências significativas, b) a discussão e reflexão dos dados e resultados que foram sendo recolhidos no decurso dos acontecimentos experienciados (tendo em consideração a cognição, a emoção e a ação, enquanto eixos fundamentais do funcionamento psicológico), c) a importância do relacionamento como facilitador da partilha de ideias e interesses, tanto dentro do grupo como entre os/as participantes e as figuras que foram suas interlocutoras nas atividades de exploração em contexto real, e d) a disponibilidade temporal para um apoio continuado, individualizado e próximo durante a implementação do projeto e para além do término deste.

Estas preocupações metodológicas foram operacionalizadas através de um plano de intervenção estruturado em seis momentos que se pressupõe corresponderem às etapas esperadas da progressão dos/as participantes na capacidade de escolher estrategicamente o local de estágio, nomeadamente: 
a) Explorar e Integrar I - proporciona-se a exploração das formas de expressão do eu na relação com as possibilidades formativas oferecidas ao longo do curso, nos diferentes anos e níveis de formação $\left(1 .^{\circ}\right.$ e $2 .^{\circ}$ ciclo) e noutros âmbitos da sua vida pessoal e social, bem como a significação destas no sentido da retirada de ilações quanto ao local de estágio ideal para o/a estudante;

b) Explorar e Integrar II - procura promover-se uma compreensão alargada do mundo do trabalho na área da Psicologia da Educação com a ênfase colocada nas oportunidades que este poderá oferecer à realização dos objetivos (formativos e/ou de realização profissional) de que cada estudante parte quando se orienta para a estrutura social de emprego;

c) Explorar e Integrar III - procura recentrar-se o/a estudante no seu próprio perfil de competências, levando/a a objetivar os saberes possuídos e a identificar os saberes (ainda) a desenvolver, de modo a estimular o questionamento das suas necessidades de formação, o realismo e a diferenciação dos objetivos (formativos e/ ou profissionais) inicialmente definidos;

d) Explorar IV - encoraja-se o/a estudante a pré seleccionar alguns contextos de estágio, levando/a a mobilizar nessa tarefa a maior diversidade possível de critérios partindo das conclusões alcançadas nos momentos de intervenção prévios, e a desenhar um projeto de exploração direta (local e presencial) desses contextos;

e) Integrar IV - as experiências de exploração direta de cada estudante são apresentadas e discutidas em grupo de uma forma que favoreça o posicionamento crítico dos/as estudantes em relação às potencialidades e limitações dos locais em causa do ponto de vista da satisfação dos objetivos (formativos e /ou profissionais) estabelecidos pelos/as estudantes;

f) Explorar V - com base nos dados obtidos aquando da exploração direta, os/as estudantes são convidados/as a focalizarem-se nas dificuldades e exigências inerentes à adaptação ao contexto preferencial de estágio curricular, procurando apoiar-se os/as estudantes a configurarem antecipadamente a sua nova identidade de papel ("estudante estagiário/a") e a definir linhas orientadoras para o seu desempenho. A integração destas questões estaria prevista para a altura em que se tivessem consumado seis meses de vivência do estágio curricular.

\section{Aspetos processuais e dados da implementação do projeto}

O projeto Keep-on-Going foi implementado na modalidade de pequeno grupo com cinco estudantes (género feminino) a frequentar o $4 .^{\circ}$ ano na área de Intervenção Psicológica, Educação e Desenvolvimento Humano, do Mestrado Integrado em Psicologia da Faculdade de Psicologia e de Ciências da Educação da Universidade do Porto (FPCEUP) ${ }^{2}$. Tratando-se de um projeto piloto, optou-se por restringir a participação a estudantes de apenas uma área de especialização para garantir que a abordagem adotada se mostraria consistente e adaptada às necessidades específicas de procura de estágio de estudantes com um determinado perfil de formação. Considerou-se, ainda, que se tratando de uma primeira iniciativa do género na Faculdade, estes seriam os estudantes mais predispostos a participar, na medida em que sendo da área da Psicologia da Educação poderia constituir para eles motivação adicional o facto de poderem observar, na forma participante, como se desenvolve um projeto de intervenção na sua própria área.

A equipa técnica do projeto compunha-se de três membros: duas psicólogas recém-diplomadas da mesma área de formação das participantes e um terceiro membro que, sendo docente da Faculdade na área em causa (embora sem lecionar nenhuma unidade curricular do ano frequentado pelas participantes tinha como função a supervisão de estágios curriculares da área) assumiu a responsabilidade pela qualidade técnico-científica do projeto e pela supervisão da própria intervenção. A intervenção decorreu no 2. ${ }^{\circ}$ semestre do ano letivo 2015/2016 entre nove de março e 16 de junho. Foram realizadas 10 sessões, com uma duração total variável de duas a três horas/cada, agendadas semanalmente numa tarde livre de atividades letivas. A estrutura geral do projeto e os conteúdos tratados em cada sessão encontram-se sistematizados no Quadro 1. A dinamização das sessões obedeceu a um planeamento sequencial que previa que cada sessão começasse com uma atividade de introdução à temática, seguindo-se a realização de tarefas exploratórias por parte dos/as participantes, e terminando com a integração do(s) assunto(s) abordado(s), tendo em vista o registo escrito

2 O curso de Psicologia da FPCEUP é constituído por dois ciclos de estudos integrados: o $1 .^{\circ}$ ciclo, com três anos de duração e com formação generalista, confere a Licenciatura em Ciências Psicológicas; o 2. ${ }^{\circ}$ ciclo, com dois anos de duração e com formação especializada, confere o grau de Mestre em Psicologia. A transição para o $2 .^{\circ}$ ciclo de estudos, requer a escolha de uma de quatro áreas de formação específica: Intervenção Psicológica, Educação e Desenvolvimento Humano; Psicologia Clínica e da Saúde; Psicologia do Comportamento Desviante e da Justiça; Psicologia das Organizações, Social e do Trabalho. O estágio curricular é realizado no último ano do $2 .^{\circ}$ ciclo de estudos $\left(5 .^{\circ}\right.$ ano do Mestrado Integrado em Psicologia) em contextos relacionados com a área de formação que os estudantes se encontrem a frequentar. A intervenção realizou-se no $4 .^{\circ}$ ano do Mestrado Integrado em Psicologia, ou seja, no $1 .^{\circ}$ ano do $2 .^{\circ}$ ciclo do curso. 
Quadro 1.

\begin{tabular}{|c|c|}
\hline Número da sessão & Temáticas e objetivos \\
\hline Sessão 0 & $\begin{array}{l}\text { - Divulgação do projeto, objetivos gerais e específicos } \\
\text { - Processo de inscrição dos estudantes }\end{array}$ \\
\hline Sessão 1 & $\begin{array}{l}\text { Explorar e Integrar I: Escolhas Académicas I } \\
\text { - Leitura e assinatura da declaração de consentimento informado } \\
\text { - Exploração da escolha do curso de Psicologia e experiências/fatores percursores }\end{array}$ \\
\hline Sessão 2 & $\begin{array}{l}\text { Explorar e Integrar I: Escolhas Académicas II e III } \\
\text { - Exploração de escolhas e experiências académicas no 1. ciclo } \\
\text { - Exploração de escolhas e experiências na área de especialização }\end{array}$ \\
\hline Sessão 3 & $\begin{array}{l}\text { Explorar e Integrar II: Objetivos e oportunidades do/no mercado de trabalho } \\
\text { - Definição do objetivo profissional futuro por cada participante } \\
\text { - Abordagem ao marketing pessoal } \\
\text { - O que o mercado tem para me oferecer? }\end{array}$ \\
\hline Sessão 4 & $\begin{array}{l}\text { Explorar e Integrar III: Perfis de Competências } \\
\text { - Exploração das competências de cada participante: análise de evidências de competências } \\
\text { possuídas e competências requeridas pelo mercado de trabalho } \\
\text { - Definição de um objetivo intermédio do desenvolvimento de competências por cada } \\
\text { participante }\end{array}$ \\
\hline Sessão 5 & $\begin{array}{l}\text { Preparação para a Exploração Direta I: Seleção dos contextos de estágio } \\
\text { - Que estágio para mim? Conhecimento da tipologia de estágios e exploração da oferta } \\
\text { formativa da Faculdade }\end{array}$ \\
\hline Sessão 6 & $\begin{array}{l}\text { Preparação para a Exploração Direta II } \\
\text { - Exploração das semelhanças entre projeto de investigação científica e projeto de exploração } \\
\text { direta } \\
\text { - Desenho de um projeto de exploração direta } \\
\text { - Projeto de Exploração Direta, Fase 1: Síntese das informações mais relevantes associadas aos } \\
\text { dois locais de estágio pré-selecionados }\end{array}$ \\
\hline Sessão 7 & $\begin{array}{l}\text { Integrar IV: Projeto de Exploração Direta, Fase } 3 \\
\text { - Apresentação do processo e dos resultados da exploração direta dos locais visitados }\end{array}$ \\
\hline Sessão 8 & $\begin{array}{l}\text { Integrar V: O estudante estagiário } \\
\text { - Exploração e reflexão sobre o papel de estudante estagiário } \\
\text {-Percepções quanto ao comportamento/desempenho esperado de um estudante estagiário e } \\
\text { significação da identidade de papel }\end{array}$ \\
\hline \multirow[t]{2}{*}{ Sessão 9} & $\begin{array}{l}\text { Sessão de finalização do projeto } \\
\text { - Esclarecimento de dúvidas } \\
\text { - Preenchimento do questionário de avaliação final } \\
\text { - Recolha de sugestões para edição futura }\end{array}$ \\
\hline & $\begin{array}{l}\text { Follow-up } \\
\text { - Envio do questionário online de follow-up }\end{array}$ \\
\hline
\end{tabular}

Sessões e Temáticas Abordadas no Projeto de intervenção Keep-on-Going

das principais conclusões ou ilações úteis para a escolha do local de estágio.

Paralelamente às sessões presenciais, o projeto dispunha de uma página no Facebook (grupo fechado), na qual eram publicados desafios para as participantes realizarem entre as sessões, disponibilizadas informações ou lembretes relativos às sessões seguintes, servindo ainda para a partilha de documentos, registos fotográficos, e colocação de dúvidas ou questões por parte das participantes. A equipa técnica mostrou-se igualmente disponível para o agendamento de reuniões individuais sempre que tal se mostrasse do interesse dos/as participantes para facultar um apoio personalizado e auxiliar em algum momento de maior incerteza e/ou ansiedade. A participação dos estudantes foi voluntária e gratuita, tendo sido salvaguardada a confidencialidade e o anonimato, nomeadamente perante 
a docente que realizou a supervisão da intervenção. As participantes tiveram acesso a um documento escrito explicativo dos objetivos e características do projeto de intervenção e assinaram, oportunamente, a declaração de Consentimento Informado. Foram observados todos os cuidados ético-deontológicos inerentes à realização de intervenção psicológica em grupo e à utilização de dados pessoais.

\section{Metodologia de avaliação do projeto}

Foi, igualmente, desenhado um dispositivo de avaliação da intervenção contemplando uma avaliação inicial de necessidades, a avaliação contínua das evoluções sessão a sessão, a avaliação final sumativa da intervenção e a avaliação de follow-up. Foram construídos para o efeito questionários de autorrelato constituídos por questões abertas e fechadas.

O questionário de avaliação inicial de necessidades, aplicado na sessão 0 , tinha como objetivo identificar os conhecimentos que cada estudante possuía sobre o estágio curricular na sua área. Pretendia, igualmente, compreender quais as perspetivas pessoais em relação à escolha do estágio. Os dados recolhidos com este questionário serviriam ainda para que a equipa pudesse verificar a adequação do planeamento, tendo em consideração as necessidades sinalizadas pelas respostas dos estudantes.No final de cada sessão, foi aplicado um questionário destinado à avaliação contínua da utilidade e qualidade da sessão, no qual se procurava conhecer a opinião das participantes sobre a relevância da sessão, aspetos positivos e menos positivos e recolha de possíveis sugestões para aperfeiçoamento do plano de sessão. De uma forma continuada, foram igualmente distribuídas fichas de apoio visando ao completamento de frases para que cada estudante pudesse registar as suas principais aprendizagens e implicações destas na sua escolha do local de estágio.

$\mathrm{Na}$ última sessão do projeto, foi aplicado um questionário que teve como objetivo a avaliação dos resultados da intervenção, tendo como propósito identificar os conhecimentos adquiridos sobre o estágio curricular na área de IPEDH e compreender as perspetivas pessoais das participantes em relação à escolha do estágio.Numa fase posterior, foi administrado o questionário de avaliação de follow-up que tinha como objetivos conhecer os acontecimentos e experiências vividas pelas participantes nos seus contextos de estágio e compreender a importância e utilidade do projeto Keep-on-Going, no que concerne à escolha estratégica e preparação para esta etapa de iniciação ao mundo profissional. As participantes responderam a este questionário a meio do seu estágio curricular, tendo sido disponibilizado e preenchido através de uma plataforma online.

\section{Resultados da avaliação do projeto Keep-On-Going e suas implicações}

A avaliação global do projeto teve como objeto de análise as respostas das participantes ao questionário de avaliação de necessidades, aos questionários de avaliação contínua, ao questionário de avaliação final e ao questionário de follow up.

As respostas das participantes ao questionário inicial permitiram verificar que se mostrava necessário que a intervenção lhes proporcionasse: (1) um conhecimento mais pormenorizado de instituições de estágio, de forma a melhor compreender a diversidade dos possíveis contextos de atuação; (2) preparação pessoal para o Estágio Curricular, em termos de procura de informação sobre o local, acesso a testemunhos reais acerca do sucedido no local de estágio escolhido,...; (3) apoio na identificação de oportunidades da área de Intervenção Psicológica, Educação e Desenvolvimento Humano, atendendo à diversidade existente de ofertas em que os estudantes podem desempenhar as suas funções; (4) formas de aproximação ao Estágio Curricular, como, por exemplo, estabelecimento de contactos com os profissionais dos locais de estágio, realização de entrevistas para conhecer o contexto e sua dinâmica, definição de datas para início do estágio, compromisso e flexibilidade de horários; (5) exploração de interesses, competências e motivações pessoais para um melhor conhecimento de si e das suas potencialidades e fragilidades; (6) avaliação da consistência/ajustamento do perfil do estudante e as características do local de estágio.

Apesar da estrutura e conteúdos do projeto estarem já substancialmente delineados, esta informação permitiu ter uma noção mais clara relativamente ao grau no qual os objetivos do projeto correspondiam às expectativas e necessidades das participantes, tendo sido possível perceber que a componente informativa teria de ser, de alguma maneira, reforçada. Em fidelidade ao modelo teórico de base e não querendo que as sessões de intervenção se convertessem em momentos de transmissão e receção de informação, é desta avaliação de necessidades que surge a decisão de criação de uma página no facebook que pudesse servir de veículo na troca de informações e, ao mesmo tempo, ser ponto de partida para a proposta de desafios que levassem as participantes na busca autónoma de informações em tempo extra-sessão.

De resto, a julgar pelos resultados da avaliação contínua, as participantes parecem não ter sentido a falta dessa componente informativa nas sessões. Os resultados mostram-se bastante positivos, na medida em que a média total (média das respostas registadas nas oito sessões) foi de, aproximadamente, seis numa escala tipo likert de 1 (nada) a 7 (excelente). Com base nestes resultados, conclui-se que, para as participantes, as sessões dois $(\underline{M}$ =7), cinco $(\underline{M}=6.7)$, seis $(\underline{M}=6.7)$ e sete $(\underline{M}=6.5)$ revelaram-se as de maior relevância no processo de apoio 
estratégico à escolha do local de estágio. De acordo com o feedback das participantes, o que mais apreciaram na sessão 2 foi a oportunidade de realizarem uma "exploração organizada" de si e a escuta ativa dos testemunhos apresentados pelas colegas, permitindo-lhes identificar áreas de interesse, assim como potenciais locais onde poderiam vir a trabalhar. Na sessão cinco destacam-se aspetos como a pesquisa faseada de potenciais locais de estágio, o aprofundamento dos seus conhecimentos sobre os locais selecionados, e o apoio dado pelas técnicas nessa seleção. No caso da sessão seis, foi identificado o apoio das técnicas no processo de construção do projeto de exploração direta. Na sessão sete destacou-se a oportunidade da discussão interpares sobre os locais de estágio visitados e apresentados ainda que, do ponto de vista da equipa técnica, seja de ter em conta em edições futuras, a disponibilização de mais tempo para a construção e implementação do projeto de exploração direta dos diferentes contextos de estágio, uma vez que isso poderia aumentar o número de contextos efetivamente explorados pelos/as participantes (cada uma delas apenas teve a oportunidade de se deslocar a um dos contextos pre-selecionados).

Não obstante, deverá ter-se em atenção as sessões um $(\underline{M}=4.3)$ e oito $(\underline{M}=2.3)$, pois foram classificadas como sendo as menos úteis para o processo de apoioà escolha estratégica do local de estágio. Apesar de a sessão um ter tido uma menor pontuação média comparativamente às restantes, as participantes mencionaram que esta sessão lhes permitiu a exploração sobre os fatores que influenciaram a escolha da área da psicologia, assim como as suas áreas de interesse. Desta forma, parece poder considerar-se que o projeto potenciou, retrospectivamente, $o$ autoconhecimento das estudantes, permitindo-lhes contemplar na escolha do local de estágio um critério que até aí não teria sido conscientizado e tomado como importante. Não obstante, considera-se que a sessão um é útil para o processo de apoio à escolha estratégica do local de estágio curricular na medida em que acrescenta elementos novos de relevo à matriz de fatores de que os estudantes poderão partir na escolha desse local. O resultado atribuído à sessão oito consiste na avaliação de apenas uma das participantes, mencionando que considera que nesta fase do projeto seria mais relevante investir o tempo da sessão na exploração de um maior número de locais de estágio para um conhecimento mais pormenorizado das ofertas existentes e das suas características.

A avaliação da sessão quatro, no que diz respeito a aprendizagens úteis para si, situou-se no ponto médio da escala $(\underline{M}=5.6)$, o que poderá significar que talvez as participantes não tenham conseguido compreender e valorizar plenamente os objetivos que a intervenção tinha em vista na sessão em causa. Para além desta sessão, talvez possa, futuramente, ser realizada uma outra, centrada na mesma temática, mas que permita aos/ás participantes traçar o seu perfil de competências como estagiários, de uma forma que os possa fazer perceber que esse perfil, apoiado em evidências concretas, pode ser o passe de entrada nas instituições que acolhem estágios e que, cada vez mais, solicitam que em vez de serem escolhidas pelos estagiários possam elas próprias passarem a escolher o/a estudante que querem a estagiar. Desta forma, os/as participantes também se aperceberiam melhor das dinâmicas que estão presentes no acesso às organizações aquando da procura do $1 .^{\circ}$ emprego.

$\mathrm{Na}$ última sessão do projeto, foi administrado o questionário de avaliação final com o objetivo de recolher informações quanto à evolução das participantes ao longo do Keep-on-Going e, de uma forma global, compreender a utilidade e relevância do projeto para as estudantes. Assim, foi possível constatar que as participantes desenvolveram uma maior consciência dos requisitos e características formais do estágio curricular, dos deveres e comportamentos esperados de um estudante a realizar estágio curricular, conhecimento das possíveis saídas profissionais na área de IPEDH, uma maior segurança em relação ao local a escolher para realização do estágio curricular e, por fim, um maior otimismo em relação ao sucesso da experiência de estágio. A partir da análise dos dados recolhidos, foi confirmada e reforçada a importância das sessões cinco, seis e sete em termos da escolha estratégica do local de estágio, sendo que as participantes apontaram como mais positivo a exploração direta dos locais de estágio, a perceção mais clara e concreta da variedade de locais em que o estágio pode ser realizado e o empenho que o projeto despoletou na procura do local que melhor se coaduna com os interesses e expectativas.

O questionário de follow-up foi administrado online seis meses após o término da intervenção, tendo sido respondido por apenas três das cinco participantes. Composto por 31 questões fechadas, e uma escala de resposta de tipo Likert de 7 pontos (1: Nada a 7: Imenso), avaliou quatro dimensões: (1) Preocupações face ao estágio curricular ("Integração na instituição do estágio"); (2) Evolução das participantes desde a primeira sessão até à sua integração no contexto de estágio ("Consciência das suas motivações e interesses"); (3) Utilidade das sessões no apoio à escolha estratégica do local de estágio curricular ("Sessão 1 - Escolhas Académicas"); (4) Qualidade geral do projeto. Globalmente, os resultados são bastante positivos especialmente no que diz respeito às dimensões "Evolução das participantes" $(\underline{M}=6.2)$ e "Utilidade do projeto" $(\underline{M}=5.8)$, o que permite concluir que, pelo menos no caso destas três participantes, o projeto Keep-on-Going parece ter cumprido os seus objetivos. $\mathrm{Na}$ medida em que as participantes percecionaram uma evolução no que diz respeito à tomada de consciência das suas motivações e interesses; competências; na gestão pessoal; na formulação de objetivos profissionais futuros; aquisição de conhecimentos sobre potenciais saídas profissionais e segurança relativamente à escolha do local 
de estágio. Quanto à dimensão "Utilidade do projeto" é possível verificar que o desenho das sessões do projeto Keep-on-Going potenciou a preparação para a escolha do local de estágio cumprindo o seu objetivo.

É de enfatizar que, atentando ao discurso das participantes nas respostas às questões abertas, se constata que os maiores ganhos percebidos por estas se situam a nível do autoconhecimento e da exploração das oportunidades ("Refletir sobre mim própria"; "Pensar mais sobre mim e o estágio"; "Fazer uma exploração organizada de mim, que me permitiu perceber o que quero e o que não quero"; "Apoio na exploração de possiveis locais de estágio"; "Perceber as áreas que mais tem interesse e possiveis locais que gostaria de trabalhar") sendo que, em geral, descrevem a participação no projeto como uma "boa experiência", "útil aos estudantes".

\section{Considerações finais}

Primeiramente, é de assinalar que a grande maioria dos alunos termina os seus cursos académicos sem conseguirem descrever de forma coerente as profissões escolhidas a que esses cursos dão acesso. Tal pode potenciar sentimentos e comportamentos pautados pela ansiedade, insegurança, falta de compromisso com o trabalho e suas exigências, e, em última instância, o abandono da profissão (Brasil, Felipe, Nora, \& Fravetto, 2012).

Com base nos resultados quantitativos e qualitativos da avaliação efetuada durante e após a implementação do projeto Keep-on-Going, parece confirmar-se a sua pertinência como intervenção no domínio do desenvolvimento vocacional em contexto universitário, no apoio à escolha estratégica do local de estágio curricular. Também a monitorização mais informal que as técnicas responsáveis pela implementação do projeto foram fazendo ao longo das nove sessões reforça essa constatação. Tanto o envolvimento e interesse (crescente) das participantes nas atividades propostas como o grau no qual as participantes progressivamente mobilizaram as conclusões alcançadas a cada sessão na orientação da sua escolha, evidenciam que o projeto influenciou a visão das participantes em relação à instrumentalidade dessa escolha e contribuiu, de um modo muito apreciável, para a segurança experienciada no momento de escolher como para a consistência da escolha feita quer no fim da intervenção quer em pleno estágio.

Tratando-se de uma iniciativa piloto, devem, no entanto, ser sublinhadas algumas limitações que foram observadas nesta primeira edição do projeto e, porventura, poderão ser colmatadas em futuras edições. Desde logo, terá de ser repensado o timing de intervenção, uma vez que tendo sido implementada no segundo semestre, não permitiu aos participantes uma exploração aprofundada das diferentes opções de escolha para local de estágio tendo em conta a elevada exigência em termos de tempo não presencial das Unidades Curriculares desta fase do plano de estudos. Talvez este seja um fator importante na compreensão dos motivos pelos quais aderiram ao projeto de intervenção muito menos estudantes do que os que se encontram inscritos na área de formação definida para recrutamento do público-alvo e do que se esperava ter sido possível envolver. Um grupo ligeiramente maior teria permitido enriquecer mais as sessões em termos da diversidade de dinâmicas e, sobretudo, da troca e confrontação de pontos de vista. É de salientar que as próprias participantes manifestaram sempre muitas dificuldades na gestão de tempo entre as tarefas académicas, extracurriculares e de cariz pessoal, sendo que esta sobrecarga e a consequente absorção a que ficavam sujeitas pelas tarefas do seu quotidiano, tornaram particularmente custoso para elas a realização de atividades de projeção no futuro. Futuramente, poderá ser considerada a possibilidade de implementação da intervenção numa fase mais inicial do ano letivo ( $1 .^{\circ}$ semestre), na qual os estudantes estão, em geral, menos assoberbados com atividades letivas e mais disponíveis para pensar no que vem a seguir em termos da escolha do local de estágio.

Também a duração do projeto poderá ser revista de modo a que seja possível: (1) dedicar mais tempo à preparação dos projetos de exploração direta (duplicando a sessão 6) e (2) dedicar um maior intervalo às sessões seis e sete a fim de permitir a deslocação dos/ as participantes a mais do que um local de estágio e, eventualmente, lhes dar a possibilidade de aí realizarem, durante um período temporal curto (três dias a uma semana) um mini-estágio experimental. A este nível, parece mostrar-se de grande relevância a utilização mais intencional de metodologias de Job Shadowing, suscetíveis de propiciarem ainda uma maior aproximação e familiarização com as atividades que os/as psicólogos/as (futuros/as orientadores/as) desenvolvem nos locais de estágio através do emparelhamento e acompanhamento direto destes pelos estudantes, e da presença no espaço e situações reais inerentes ao dia-a-dia do/a profissional (Jardim \& Nascimento, 2018).

De igual modo, sugere-se que o follow-up da intervenção possa ser feito de modo mais continuado após o término do projeto e, inclusive, na forma de sessões presenciais de periodicidade mensal. Idealmente, tais sessões poderiam ser planeadas de um modo que permitisse prosseguir o trabalho de apoio à pré configuração do papel de "estudante estagiário de psicologia" iniciado na sessão oito do projeto ampliando, com base já na experiência de role-taking, a compreensão dos estagiários quanto aos comportamentos a exibir em situações mais sensíveis e/ ou complexas da sua relação com o/a orientador/a, com os/as clientes e/ou com a instituição de estágio e seus/suas profissionais.

Para além das alterações sugeridas, admite-se que outras possam mostrar-se necessárias não só para 
aumentar a qualidade geral do projeto como para o ajustar, tomando-o como proposta-base de intervenção a outros públicos. Com efeito, é de enfatizar que o Keep-on-Going tem a vantagem de estar desenhado, em termos estruturais e substantivos, de uma forma que permite a sua implementação com grupos de estudantes de outras áreas da Psicologia e mesmo com estudantes de outros domínios de formação superior ou, até, não superior. Ao promover a exploração e a clareza de intenções de escolha numa fase prévia à do estágio académico poder-se-á mostrar útil como experiência de desenvolvimento pessoal, vocacional e, a prazo, profissional, para todos os jovens cujo processo formativo coloque perante a necessidade (ou possibilidade) de escolherem o local de estágio em que pretendem ensaiar-se como profissionais pela primeira vez.

\section{Referências}

Balbinotti, M. A. A. (2003). A noção de transcultural de maturidade vocacional na teoria de Donald Super. Psicologia reflexão e crítica, 16(3), 463-471. doi:10.1590/S0102-79722003000300005

Bolhão, A. F. J. (2013). Contribuição do estágio curricular para a formação académica e profissional dos estagiários - Estudo de caso numa instituição de ensino superior. Dissertação de Mestrado não publicada. Instituto Superior Miguel Torga, Coimbra.

Brasil, V., Felipe, C., Nora, M. M., \& Fravetto, R. (2012). Orientação profissional e planejamento de carreira para universitários. Caderno Académico Palhoça, SC, 4(1), 117-131.

Bronfenbrenner, U. (1979). The ecology of human development. Cambridge: Harvard University Press.

Campos, B. P. (1991). Educação e Desenvolvimento Pessoal e Social. Porto: Afrontamento.

Campos, B. P., \& Coimbra, J. L. (1991). Consulta Psicológica e exploração do investimento vocacional. Cadernos de Consulta Psicológica, 7, 11-19.

Cardoso, J. (coord), Varanda, M., Madruga, P., Escária, V. \& Ferreira, V. (2012). Empregabilidade e Ensino Superior em Portugal. Instituto de Ciências Sociais da Universidade de Lisboa: Lisboa.

Coimbra, J. L. (1997/1998). O meu "Grande" projecto de vida ou os meus "Pequenos" projectos: linearidade ou recorrência no desenvolvimento vocacional e suas implicações educativas. Cadernos de Consulta Psicológica, 13-14, 21-27.

Coimbra, J. L., Campos, B. P., \& Imaginário, L. (1994, 17 a 22 de Julho, Madrid). Career Intervention from a Psychological Perspective: Definition of the Main Ingredients of an Ecological developmental Methodology. Trabalho apresentado no 23rd International Congress of Applied Psychology, in the Symposium on "Recent Evolutions and Contributions of/for the Practices of Career Psychological Intervention”. Recuperado em 05 de Janeiro de 2018, em https://www.researchgate.net/publication/37650252_Career_intervention_from_a_psychological_perspective_Definition_of_the_main_ingredients_of_an_ecological-developmental_methodology.

Gonçalves, C. M. (2006). A Família e a construção de projectos vocacionais de adolescentes e jovens. Tese de Doutoramento não publicada, Faculdade de Psicologia e de Ciências da Educação da Universidade do Porto.

Gonçalves, C. M. (2000). Desenvolvimento Vocacional e promoção de competências. Recuperado em: 26 de Dezembro de 2017, de http://www.psicologia.pt/artigos/ver_artigo.php?codigo=A0123\&area=d7\&subarea.

Gonçalves, C. M. (1997). A influência da família no desenvolvimento vocacional de adolescentes e jovens. Dissertação de Mestrado não publicada, Faculdade de Psicologia e de Ciências da Educação da Universidade do Porto.

Imaginário, L. (1990). Os jovens e o trabalho: desenvolvimento vocacional dos jovens. In B. P. Campos (Ed.), Psicologia do Desenvolvimento e Educação dos Jovens (pp. 187-212). Lisboa: Universidade Aberta.

Jardim, C., \& Nascimento, I. (2018). Educação para o trabalho e desenvolvimento vocacional: contributos para uma metodologia de Job Shadowing. Revista Educação em Debate, 40(77), 75 - 90.

Monteiro, A. M., \& Gonçalves, C. M. (2011). Desenvolvimento vocacional no ensino superior: satisfação com a formação e desempenho académico. Revista Brasileira de Orientação Profissional, 12(1), 15-27.

Oliveira, M. C. (2007). Desenvolvimento e maturidade de carreira de estudantes universitários: validação de instrumentos de medida. Dissertação de Mestrado não publicada. Universidade Federal de Uberlândia, Brasil. 
Soares, A P. (1998). Desenvolvimento vocacional de jovens adultos: a exploração, a indecisão e o ajustamento vocacional em estudantes universitários. Dissertação de Mestrado. Universidade do Minho, Braga.

Taveira, M. C. (2004). Exploração e desenvolvimento vocacional na adolescência: contributos para uma abordagem sistemática e colaborativa. Psicologia e Educação, 3(1), 109-120.

Submetido: 07/02/18

Aceito: $18 / 03 / 19$

Sobre as autoras:

Inês Nascimento, PhD é Professora Auxiliar da Faculdade de Psicologia e de Ciências da Educação da Universidade do Porto.

Soraia Ferreira, Mestre em Psicologia é Mestre em Psicologia.

Priscila Rodrigues, Mestre em Psicologia é Mestre em Psicologia. 